\title{
Endovascular Abdominal Aortic Aneurysm Repair under General Anesthesia Does Not Decrease Perioperative Myocardial Ischemic Events Compared with Open Repair
}

\author{
Noriko Nanishi ${ }^{1}$, Ken Yamaura ${ }^{2}$, Katsuyuki Matsushita ${ }^{3}$, Kozaburo Akiyoshi ${ }^{3}$, Yuji Karashima ${ }^{2}$, \\ Midoriko Higashi ${ }^{2}$, Sumio Hoka ${ }^{1}$ \\ ${ }^{1}$ Department of Anesthesiology and Critical Care, Graduate School of Medicine, Kyushu University, Fukuoka, Japan; ${ }^{2}$ Operating \\ Rooms, Kyushu University Hospital, Fukuoka, Japan; ${ }^{3}$ Department of Anesthesiology and Critical Care, Kyushu University Hospital, \\ Fukuoka, Japan. \\ Email: keny@kuaccm.med.kyushu-u.ac.jp
}

Received January $18^{\text {th }}$, 2013; revised February $20^{\text {th }}$, 2013; accepted March $3^{\text {rd }}, 2013$

\begin{abstract}
Objectives: Endovascular abdominal aortic aneurysm repair (EVAR) is a common procedure for abdominal aortic aneurysm (AAA), based on minimal invasiveness compared with open surgical repair (OSR). However, general anesthesia can cause considerable perturbations in patients with AAA undergoing operative repair. The aim of this study was to compare the incidence of myocardial ischemic events in association with hemodynamic changes during EVAR and OSR under general anesthesia. Methods: We retrospectively reviewed the anesthetic and medical records of patients who underwent elective abdominal aortic aneurysm repair. ST segment changes on electrocardiography and hemodynamic changes were reviewed by the attending physicians. Results: Among 120 patients, EVAR and OSR were performed in 81 and 39 patients, respectively. There were no significant differences in preoperative morbidity between the two groups. The amount of estimated blood loss was significantly lower in EVAR than OSR. The incidence of ST-segment changes in the two groups (EVAR: 16\%, OSR: 23\%) was not statistically different. ST segment changes occurred mainly postoperatively at resolution of anesthesia in EVAR, compared with intraoperatively in OSR. ST segment changes were mostly accompanied by tachycardia in EVAR patients, whereas they were associated with hypotension in OSR. Conclusion: Our results demonstrated a comparable incidence of perioperative ST segment changes under general anesthesia in EVAR and OSR. Patients who undergo EVAR and develop tachycardia are at risk of myocardial ischemia at resolution of anesthesia.
\end{abstract}

Keywords: Abdominal Aortic Aneurysm (AAA); Anesthesia; General; Vascular Surgery; EVAR; Complication; Cardiac; Myocardial Ischemia

\section{Introduction}

Repair of abdominal aortic aneurysm (AAA) is a highrisk surgery. Patients with AAA also have high risk factors including hypercholesterolemia, hypertension, ischemic heart disease, renal insufficiency and cerebrovascular disease [1].

Open surgical repair (OSR) was a common procedure for AAA until the introduction of endovascular repair (EVAR) in the early 1990s. Since then, EVAR has become an alternative popular technique for AAA. EVAR is considered to be less invasive and better tolerated by the cardiovascular system than OSR [1-8]. The perioperative mortality and cardiac complications in EVAR are fewer than in OSR [1-4], while long-term cardiovascular mortality appears to be similar between the two procedures [2,5-9]. Perioperative asymptomatic cardiac damage after EVAR is associated with poor long-term outcome [10].

Since perioperative cardiac complications can occur after both operative and anesthetic techniques, patients who undergo EVAR may be at considerably high perioperative cardiovascular risk, such as perturbation of hemodynamics and fluid imbalance, under general anesthesia. Especially, general anesthesia could be associated with adverse cardiac outcome after EVAR compared with regional local anesthesia [11]. In this study, we compared the incidence of myocardial ischemia during EVAR and OSR performed under general anesthesia. We also investigated the hemodynamic factors associated with perioperative myocardial ischemic events in EVAR and OSR. 


\section{Methods}

After approval by the institutional review board of Kyushu University Hospital (Fukuoka, Japan) and written informed consent, we reviewed the anesthetic and medical records of all patients who underwent elective AAA repair between March 1, 2009 and January 31, 2011 at Kyushu University Hospital.

All surgical procedures were performed by experienced vascular surgeons. The choice of the procedure was left to the discretion of the vascular surgeons and was mainly based on patient preference. Endovascular repair was carried out through the femoral route with available stents and protection devices.

Both EVAR and OSR were conducted under general anesthesia according to our institutional protocol. Anesthesia was induced with fentanyl $(0.8-2 \mu \mathrm{g} / \mathrm{kg})$ and propofol (1 - $4 \mathrm{mg} / \mathrm{kg})$. After endotracheal intubation under muscle relaxation with vecuronium $(0.1 \mathrm{mg} / \mathrm{kg})$, anesthesia was maintained with continuous infusion of propofol (3 - $4 \mathrm{mg} / \mathrm{kg} / \mathrm{hr}$ ) or sevoflurane (1\% - 2\%), and remifentanil $(0.1-0.5 \mu \mathrm{g} / \mathrm{kg} / \mathrm{hr})$. Epidural anesthesia with $0.2 \%$ rocuronium $(5 \mathrm{ml} / \mathrm{hr}$ ) was used for OSR when possible as a tool for post-operative pain management.

Patients were continuously monitored with a 5-lead digital ECG recorder (BSS-9800; Nihon Kohden Co., Tokyo, Japan) in the operation room, starting before induction of anesthesia until leaving the room after recovery from anesthesia. Episodes of ischemia were defined as reversible ST-segment changes lasting $>1$ minute and shift from baseline to $>0.1 \mathrm{mV}(1 \mathrm{~mm})$. The baseline ST-segment level was defined as the average ST segment during a stable period preceding each ischemic episode. The detected ischemic changes were retrospectively reviewed and evaluated by two independent physicians.

Continuous data were expressed as mean \pm SD or mean values and ranges. Data were analyzed using Student's t-test or Mann-Whitney test. Categorical data were analyzed using the chi-square test. A $P$ value $<0.05$ was considered statistically significant. Statistical analyses were computed with JMP7 (SAS Institute Inc., Cary, NC).

\section{Results}

During the study period, EVAR was performed in 81 patients and OSR in 39 patients. The patient characteristics are listed in Table 1. There were no significant differences in preoperative morbidity and cardiovascular medications between the two groups.

Table 2 lists intraoperative data of the two groups. The duration of operation, the amount of blood loss and fluid infusion were significantly less in EVAR than in OSR. The frequency of perioperative hypotension (systolic
Table 1. Patients's characteristics.

\begin{tabular}{|c|c|c|c|}
\hline Parameter & $\operatorname{EVAR}(\mathrm{n}=81)$ & OSR $(n=39)$ & $P$ value \\
\hline Mean age (yr) [range] & $74[48-89]$ & $71[61$ - 87] & N.S. \\
\hline Men & $73(90 \%)$ & 32 (82\%) & N.S. \\
\hline ASA physical status $1,2,3$ & $0,59,22$ & $1,29,9$ & N.S. \\
\hline Size of aneurysm $(\mathrm{cm})$ & $5.3 \pm 1.0$ & $5.2 \pm 1.0$ & N.S. \\
\hline \multicolumn{4}{|l|}{ History of previous diseases } \\
\hline Ischemic heart disease & $21(26 \%)$ & $14(36 \%)$ & N.S. \\
\hline Coronary revascularization & $12(15 \%)$ & $9(23 \%)$ & N.S. \\
\hline Cerebrovascular event & $25(31 \%)$ & $11(28 \%)$ & N.S. \\
\hline \multicolumn{4}{|l|}{ Current disorders } \\
\hline Hypertension & $65(80 \%)$ & $33(85 \%)$ & N.S. \\
\hline Hyperlipidemia & 37 (46\%) & $21(54 \%)$ & N.S. \\
\hline Diabetes mellitus & $25(31 \%)$ & $9(23 \%)$ & N.S. \\
\hline Renal failure & $10(12 \%)$ & $4(10 \%)$ & N.S. \\
\hline Current or past smoker & $60(74 \%)$ & $23(59 \%)$ & N.S. \\
\hline \multicolumn{4}{|l|}{ Medications at admission } \\
\hline Aspirin & $34(42 \%)$ & 19 (49\%) & N.S. \\
\hline Antiplatelet agents & $44(54 \%)$ & $21(54 \%)$ & N.S. \\
\hline Anticoagulants & $6(7 \%)$ & $3(8 \%)$ & N.S. \\
\hline $\begin{array}{l}\text { Angiotensin converting } \\
\text { enzyme inhibitors }\end{array}$ & $28(35 \%)$ & $12(31 \%)$ & N.S. \\
\hline $\begin{array}{l}\text { Angiotensin receptor } \\
\text { blockers }\end{array}$ & $18(22 \%)$ & $7(18 \%)$ & N.S. \\
\hline$\beta$ blockers & $21(26 \%)$ & $13(33 \%)$ & N.S. \\
\hline Calcium channel blockers & 49 (60\%) & 25 (64\%) & N.S. \\
\hline
\end{tabular}

EVAR: endovascular abdominal aortic aneurysm repair; OSR: open surgical abdominal aortic aneurysm repair.

Table 2. Surgical details.

\begin{tabular}{cccc}
\hline Outcome & EVAR (n=81) & OSR (n=39) & $P$ value \\
\hline $\begin{array}{c}\text { Duration of operation (min) } \\
\text { Duration of anesthesia (min) }\end{array}$ & $193 \pm 89$ & $253 \pm 102$ & $<0.001$ \\
$\begin{array}{c}\text { Blood loss during } \\
\text { operation (g) }\end{array}$ & $345 \pm 257$ & $1754 \pm 1603$ & $<0.001$ \\
$\begin{array}{c}\text { Fluid infusion } \\
\text { during operation (l) }\end{array}$ & $2.4 \pm 0.9$ & $5.1 \pm 2.4$ & $<0.001$ \\
$\begin{array}{c}\text { Intraoperative } \\
\text { complications (n) }\end{array}$ & $52(63 \%)$ & $27(69 \%)$ & N.S. \\
$\begin{array}{c}\text { Hypotension (n) } \\
\text { Hypertension (n) }\end{array}$ & $23(28 \%)$ & $12(31 \%)$ & N.S. \\
$\begin{array}{c}\text { Arrhythmia (n) } \\
\text { Increased A-a DO } \mathrm{DO}_{2}(\mathrm{n})\end{array}$ & $22(27 \%)$ & $7(10 \%)$ & N.S. \\
\hline
\end{tabular}

EVAR: endovascular abdominal aortic aneurysm repair; OSR: open surgical abdominal aortic aneurysm repair. 
blood pressure $<70 \mathrm{mmHg}$ ) was significantly higher in OSR than EVAR.

ST-segment changes were detected in 13 (16\%) patients of the EVAR group and 9 (23\%) patients of the OSR group ( $\mathrm{P}=\mathrm{NS}$ ) (Table 3). In EVAR, ST-segment changes occurred before or after operation in 10 of the 13 patients. The ST-segment changes in 8 of 13 patients occurred especially after operation while arousing from anesthesia ( $p=0.04$ for OSR vs. EVAR). By contrast, all ST-segment changes occurred during surgical procedure in OSR ( $p=0.01$ for OSR vs. EVAR). The ST-segment changes in EVAR were accompanied with tachycardia ( $p$ $=0.01$ for OSR vs. EVAR) (Figure 1), whereas those in OSR were associated with hypotension $(p=0.03$ for OSR vs. EVAR).

Patients were discharged on average at postoperative day 9 in EVAR and day 18 in OSR ( $p=0.01$, Table 4). The all-cause mortality and incidence of postoperative complications were $5 \%$ (4 patients) and 20\% (7 patients), respectively. One patient of the EVAR group developed paraplegia, 3 patients of the OSR group developed postoperative aspiration pneumonia, and 4 of the OSR group had gastrointestinal complications, such as bleeding from gastric ulcer and ischemic enteritis (Table 4).

Three patients who underwent EVAR required re-operations because of end-graft leakage. During the followup, 2 patients of the EVAR group died of cerebellar hemorrhage and heart disease, and one patient of the OSR group died of ischemic colitis. Two patients of the EVAR group and 1 of the OSR group suffered brain hemorrhage (Table 5).

Table 3. ST-segment changes.

\begin{tabular}{cccc}
\hline & EVAR (n=81) & OSR (n=39) & $P$ value \\
\hline ST-segment changes (n) & $13(16 \%)$ & $9(23 \%)$ & N.S. \\
Anesthetic induction period & $2(2 \%)$ & $0(0 \%)$ & N.S. \\
Intra-operative period & $5(6 \%)$ & $9(23 \%)$ & 0.01 \\
Anesthetic arousal period & $8(10 \%)$ & $0(0 \%)$ & 0.04 \\
\hline
\end{tabular}

EVAR: endovascular abdominal aortic aneurysm repair; OSR: open surgical abdominal aortic aneurysm repair.

Table 4. Postoperative outcome.

\begin{tabular}{lccc}
\hline & EVAR (n = 81) & OSR (n = 39) & $P$ value \\
\hline $\begin{array}{c}\text { Hospitalization days after } \\
\text { operation (range) }\end{array}$ & $9(6-49)$ & $17(8-86)$ & $<0.001$ \\
$\begin{array}{c}\text { Mortality at } 30 \text { days (n) } \\
\text { Mortality at } 1 \text { year (n) }\end{array}$ & $0(0 \%)$ & $1(3 \%)$ & N.S. \\
\hline
\end{tabular}

EVAR: endovascular abdominal aortic aneurysm repair; OSR: open surgical abdominal aortic aneurysm repair.
Table 5. Postoperative complications.

\begin{tabular}{cccc}
\hline Outcome & EVAR $(\mathrm{n}=81)$ & OSR $(\mathrm{n}=39)$ & $P$ value \\
\hline Postoperative complications & $4(5 \%)$ & $7(20 \%)$ & 0.037 \\
Aspiration pneumonia & $0(0 \%)$ & $3(7 \%)$ & 0.013 \\
$\begin{array}{c}\text { Re-operation } \\
\text { Gastrointestinal } \\
\text { complications }\end{array}$ & $4(5 \%)$ & $1(3 \%)$ & N.S. \\
$\begin{array}{c}\text { Paraplegia } \\
\begin{array}{c}\text { Perioperative } \\
\text { myocardialinfarction }\end{array}\end{array}$ & $1(1 \%)$ & $4(10 \%)$ & 0.032 \\
Cerebral hemorrhage & $2(2 \%)$ & $0(0 \%)$ & N.S. \\
\hline
\end{tabular}

EVAR: endovascular abdominal aortic aneurysm repair; OSR: open surgical abdominal aortic aneurysm repair.

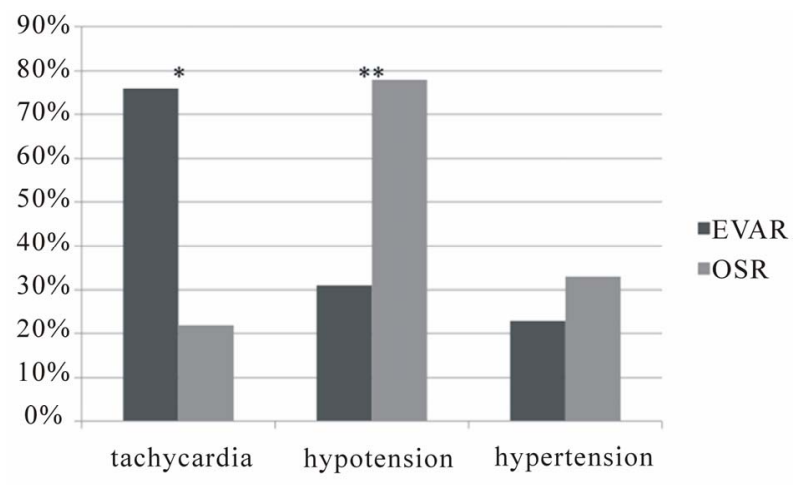

Figure 1. Related causes of ST segment changes.

\section{Discussion}

The reported incidence of myocardial ischemia during elective OSR is as high as $20 \%-40 \%[6,12]$ and it has been demonstrated to be a strong predictor of subsequent clinical cardiovascular events [12,13]. The incidence of ischemic ST-changes in the present study of $23.1 \%$ in patients undergoing OSR is consistent with those of previous reports. On the other hand, our study also showed that the incidence of myocardial ischemic events during EVAR were comparable to those during OSR (15.7\% vs. 23.1\%). These findings are inconsistent with the study of Feringa et al. [2]. They showed a significantly lower incidence of perioperative myocardial ischemia during EVAR (10.2\%) compared with OSR (43.7\%), although the long-term mortality rate and cardiac events were not significantly different. The lower incidence of perioperative myocardial ischemia was considered by these investigators to be due to the less invasive procedure in EVAR than OSR.

Factors associated with perioperative myocardial ischemic events include operative and anesthetic stress, which can cause hemodynamic perturbations and myocardial oxygen supply and demand imbalance. Feringa et 
al. [2] reported significantly longer duration of operation and larger total fluid infusion for OSR than EVAR. They also showed that the heart rate during and after operation was significantly higher in OSR compared with EVAR (68 and 74 beats/min during operation and 72 and 81 beats/min after operation in OSR and EVAR, respectively). They concluded that the higher heart rate in OSR is likely the result of increased surgical stress and sympathetic tone. However, EVAR was performed under regional anesthesia whereas OSR was performed under general anesthesia in their study [2]. Therefore, the lower incidence of myocardial ischemia in EVAR in their study may be due to not only to less surgical stress of EVAR but also less anesthetic stress in EVAR compared with OSR.

As far as anesthetic methods are concerned, various techniques have been applied in EVAR, including general anesthesia, epidural and spinal anesthesia, and local anesthesia, with or without monitored anesthesia care [2, 14-16]. The choice of the anesthetic technique is based mainly on the preference of the surgeons and anesthetists. Various outcome results are reported with respect to the anesthetic technique for EVAR [17-20]. The reasons for the variable results may be related to biases in the selected anesthetic technique as well as patient-specific factors such as anatomy, medical risk, available resources, and procedural complexity. Previous studies using multivariate analysis showed that locoregional anesthetic techniques are associated with low rates of cardiac complications [18,19], especially those used for EVAR [19, 20]. Recent report also clearly shows that general anesthesia is associated with adverse cardiac outcome after EVAR compared with regional anesthesia [11].

In our hospital, general anesthesia is routinely selected for EVAR and OSR, in order to reduce anxiety of AAA patients, to avoid unintentional movement, and to apply prompt treatment for any cardiac and pulmonary complications. Our results showed that EVAR under general anesthesia is associated with similar perioperative cardiac risks compared with OSR for AAA patients. It is noteworthy that the timing and causes of ST segment changes on the ECG were different between EVAR and OSR. Generally, most of myocardial ischemia has been reported to occur intra-operatively or during the post-operative period in association with hemodynamic changes such as tachycardia, hypertension or hypotension in patients with AAA repair [21-23]. In our study, ST segment changes occurred most frequently soon after operation at arousal from anesthesia in EVAR in association with tachycardia, while such changes occurred during operation in OSR in association with hypotension.

Intraoperative heart rate was well controlled by the use of remifentanil and supplemental sevoflurane anesthesia during EVAR. However, at resolution of anesthesia, acute withdrawal of remifentanil, insufficient pain control, and shivering or non-shivering thermogenesis may cause an increase in sympathetic activity resulting in tachycardia in EVAR. On the other hand, hypotension caused by hemorrhage or aortic unclamping may be the cause of ischemic events in OSR. The lack of ST segment changes at resolution of anesthesia in OSR might be related to the use of thoracic epidural anesthesia. Epidural anesthesia can reduce postoperative stress and myocardial oxygen demand [24-26].

The major limitation of this study is that troponin $\mathrm{T}$ was not measured in association with ST segment changes. Therefore, ischemic ST segment changes identified in our study could not be diagnosed directly with substantial myocardial ischemia. Another limitation is that the operative procedures were not randomly assigned to the patients. Although the baseline clinical characteristics including ASA status, aneurismal size and co-morbidity were comparable between the EVAR and OSR groups (Table 1), our medical team might have inadvertently selected EVAR rather than OSR for severely compromised patients. Therefore, it is possible that tolerance to anesthesia was different between the two groups.

In conclusion, our results suggest that EVAR performed under general anesthesia is not associated with a lower incidence of ST segment changes compared with OSR. EVAR remains to be associated with a similar risk for myocardial ischemia, therefore meticulous cardiac examination and anesthetic care should be exercised when this procedure is selected, similar to OSR.

\section{Acknowledgements}

The authors thank F.G. Issa, MD, PhD (www.word-medex.com.au) for careful reading and editing the manuscript.

\section{REFERENCES}

[1] T. J. Wilt, F. A. Lederle, R. MacDonald, Y. C. Jonk, T. S. Rector and R. L. Kane, "Comparison of Endovascular and Open Surgical Repairs for Abdominal Aortic Aneurysm,” Evidence Report-Technology Assessment, Vol. 144, 2006, pp. 1-113.

[2] H. H. Feringa, S. Karagiannis, R. Vidakovic, P. G. Noordzij, J. J. Brugts, O. Schouten, M. R. vanSambeek, J. J. Bax and D. Poldermans, "Comparison of the Incidences of Cardiac Arrhythmias, Myocardial Ischemia, and Cardiac Events in Patients Treated with Endovascular versus Open Surgical Repair of Abdominal Aortic Aneurysms,” American Journal of Cardiology, Vol. 100, No. 9, 2007, pp. 1479-1484. doi:10.1016/j.amjcard.2007.06.043

[3] O. Schouten, V. H. van Waning, M. D. Kertai, H. H. Feringa, J. J. Bax, E. Boersma, A. Elhendy, E. Biagini, M. R. van Sanbeek, H. van Urk and D. Poldermans, "Periopera- 
tive and Long-Term Cardiovascular Outcomes in Patients Undergoing Endovascular Treatment Compared with Open Vascular Surgery for Abdominal Aortic Aneurysm or Iliaco-Femoro-Popliteal Bypass," American Journal of Cardiology, Vol. 96, No. 6, 2005, pp. 861-866. doi:10.1016/j.amjcard.2005.05.036

[4] M. Prinssen, E. L. Verhoeven, J. Buth, P. W. Cuypers, M. R. van Sambeek, R. Balm, E. Buskens, D. E. Grobbee, J. D. Blankensteijn and Dutch Randomized Endovascular Aneurysm Management (DREAM) Trial Group, “A Randomized Trial Comparing Conventional and Endovascular Repair of Abdominal Aortic Aneurysms,” The New England Journal of Medicine, Vol. 351, No. 16, 2004, pp. 1607-1618. doi:10.1056/NEJMoa042002

[5] L. C. Brown, S. G. Thompson, R. M. Greenhalgh, J. T. Powell and Endovascular Aneurysm Repair Trial Participants, "Incidence of Cardiovascular Events and Death After Open or Endovascular Repair of Abdominal Aortic Aneurysm in the Randomized EVAR Trial 1," British Journal of Surgery, Vol. 98, No. 7, 2011, pp. 935-942. doi:10.1002/bjs.7485

[6] EVAR Trial Participants, "Endovascular Aneurysm Repair and Outcome in Patients Unfit for Open Repair of Abdominal Aortic Aneurysm (EVAR Trial 2): Randomized Control Trial,” Lancet, Vol. 365, No. 9478, 2005, pp. 2187-2192. doi:10.1016/S0140-6736(05)66628-7

[7] M. V. Raval and M. K. Eskandari, "Outcomes of Elective Abdominal Aortic Aneurysm Repair among the Elderly: Endovascular versus Open Repair," Surgery, Vol. 151, No. 2, 2012, pp. 245-260. doi:10.1016/j.surg.2010.10.022

[8] United Kingdom EVAR Trial Investigators, R. M. Greenhalgh, L. C. Brown, J. T. Powell, S. G. Thompson, D. Epstein and M. J. Sculpher, "Endovascular versus Open Repair of Abdominal Aortic Aneurysm,” The New England Journal of Medicine, Vol. 362, No. 20, 2010, pp. 18631871. doi:10.1056/NEJMoa0909305

[9] EVAR Trial Participants, "Endovascular Aneurysm Repair versus Open Repair in Patients with Abdominal Aortic Aneurysm (EVAR Trial 1): Randomised Controlled Trial,” Lancet, Vol. 365, No. 9478, 2005, pp. 2179-2186. doi:10.1016/S0140-6736(05)66627-5

[10] T. A. Winkel, O. Schouten, J. P. van Kuijk, H. J. Verhagen, J. J. Bax and D. Poldermans, "Perioperative Asymptomatic Cardiac Damage after Endovascular Abdominal Aneurysm Repair Is Associated with Poor Long-Term Outcome,” Journal of Vascular Surgery, Vol. 50, No. 4, 2009, pp. 749-754. doi:10.1016/j.jvs.2009.04.069

[11] E. J. Bakker, K. M. van de Luijtgaarden, F. van Lier, T. M. Valentijn, S. E. Hoeks, M. Klimek, H. J. Verhangen and R. J. Stolker, "General Anaesthesia Is Associated with Adverse Cardiac Outcome after Endovascular Aneurysm Repair," European Journal of Vascular \& Endovascular Surgery, Vol. 44, No. 2, 2012, pp. 121-125. doi:10.1016/j.ejvs.2012.04.028

[12] P. W. Cuypers, M. Gardien, J. Buth, C. H. Peels, J. A. Charbon and W. C. Hop, "Randomized Study Comparing Cardiac Response in Endovascular and Open Abdominal Aortic Aneurysm Repair,” British Journal of Surgery, Vol. 88, No. 8, 2001, pp. 1059-1065.

\section{doi:10.1046/j.0007-1323.2001.01834.x}

[13] The Study of Perioperative Ischemia Research Group, “Association of Perioperative Myocardial Ischemia with Cardiac Morbidity and Mortality in Men Undergoing NonCardiac Surgery," The New England Journal of Medicine, Vol. 323, No. 26, 1990, pp. 1781-1788. doi:10.1056/NEJM199012273232601

[14] P. Cao, S. Zannetti, G. Parlani, F. Verzini, S. Caporali, A. Spaccatini and F. Barzi, "Epidural Anesthesia Reduces Length of Hospitalization after Endoluminal Abdominal Aortic Aneurysm Repair,” Journal of Vascular Surgery, Vol. 30, No. 4, 1999, pp. 651-657. doi:10.1016/S0741-5214(99)70104-7

[15] J. P. Henretta, K. J. Hodgson, M. A. Mattos, L. A. Karch, S. N. Hurlbert, Y. Sternbach, D. E. Rmsey and D. S. Sumner, "Feasibility of Endovascular Repair of Abdominal Aortic Aneurysms with Local Anesthesia with Intravenous Sedation,” Journal of Vascular Surgery, Vol. 29, No. 5, 1999, pp. 793-798. doi:10.1016/S0741-5214(99)70205-3

[16] C. De Virgilio, L. Romero, C. Donayre, K. Meek, R. J. Lewis, M. Lippmann, C. Rodriguez and R. White, "Endovascular Abdominal Aortic Aneurysm Repair with General versus Local Anesthesia: A Comparison of Cardiopulmonary Morbidity and Mortality Rates," Journal of Vascular Surgery, Vol. 36, No. 5, 2002, pp. 988-991. doi:10.1067/mva.2002.128314

[17] J. R. Parra, T. Crabtree, R. B. McLafferty, J. Ayerdi, L. A. Gruneiro, D. E. Ramsey and K. J. Hodgson, “Anesthesia Technique and Outcomes of Endovascular Aneurysm Repair,” Annals of Vascular Surgery, Vol. 19, No. 1, 2005, pp. 123-129. doi:10.1007/s10016-004-0138-y

[18] V. Ruppert, L. J. Leurs, B. Steckmeier, J. Buth and T. Umscheid, "Influence of Anesthesia Type on Outcome after Endovascular Aortic Aneurysm Repair: An Analysis Based on Eurostar Data," Journal of Vascular Surgery, Vol. 44, No. 1, 2006, pp. 16-21. doi:10.1016/j.jvs.2006.03.039

[19] V. Ruppert, L. J. Leurs, J. Rieger, B. Steckmeier, J. Buth, T. Umscheid and EUROSTAR Collaborators, "Risk-Adapted Outcome after Endovascular Aortic Aneurysm Repair: Analysis of Anesthesia Types Based on Eurostar Data," Endovascular Aneurysm Repair, Vol. 14, No. 1, 2007, pp. 12-22. doi:10.1583/06-1957.1

[20] E. L. G. Verhoeven, C. S. Cina, I. F. J. Tielliu, C. J. Zeebregts, T. R. Prins, G. B. Eindhoven, M. M. Span, M. R. Kapma and J. J. van den Dungen, "Local Anesthesia for Endovascular Abdominal Aortic Aneurysm Repair,” Journal of Vascular Surgery, Vol. 42, No. 3, 2005, pp. 402 409. doi:10.1016/j.jvs.2005.05.047

[21] Z. A. Ali, C. J. Callaghan, A. A. Ali, A. Y. Sheikh, A. Akhtar, A. Pavlovic, S. A. Nouraei, D. P. Dutka and M. E. Gaunt, "Perioperative Myocardial Injury after Elective Open Abdominal Aortic Aneurysm Repair Predicts Outcome," European Journal of Vascular \& Endovascular Surgery, Vol. 35, No. 4, 2008, pp. 420-421. doi:10.1016/j.ejvs.2007.10.007

[22] S. Garcia, J. E. Rider, T. E. Moritz, G. Pierpont, S. Gold- 
man, G. C. Larsen, K. Shunk, F. Littooy, S. Santilli, J. Rapp, D. J. Reda, H. B. Ward and E. O. McFalls, "Preoperative Coronary Artery Revascularization and LongTerm Outcomes Following Abdominal Aortic Vascular Surgery in Patients with Abdominal Myocardial Perfusion Scans: A Subgroup Analysis of the Coronary Artery Revascularization Prophylaxis Trial," Catheterization and Cardiovascular Interventions, Vol. 77, No. 1, 2011, pp. 134-141. doi:10.1002/ccd.22699

[23] G. Landesberg, M. Mosseri, D. Zahger, Y. Wolf, M. Perouansky, H. Anner, B. Drenger, Y. Hasin, Y. Berlatzky and C. Weissman, "Myocardial Infarction after Vascular Surgery: The Role of Prolonged, Stress-Induced, ST Depression-Type Ischemia," Journal of the American College of Cardiology, Vol. 37, No. 7, 2001, pp. 1389-1345. doi:10.1016/S0735-1097(01)01265-7

[24] L. N. Diebel, M. P. Lange, F. Schneider, K. Mason, R. F. Wilson, L. Jacobs and M. S. Dahn, "Cardiopulmonary
Complications after Major Surgery: A Role of Epidural Anesthesia?” Surgery, Vol. 102, No. 4, 1987, pp. 660666.

[25] M. S. Gold, D. DeCrosta, C. Rizzuto, R. R. Ben-Harari and S. Ramanathan, "The Effect of Lumbar Epidural and General Anesthesia on Plasma Catecholamines and Hemodynamics during Abdominal Aortic Aneurysm Repair,” Anesthesia \& Analgesia, Vol. 78, No. 2, 1994, pp. 225-230. doi:10.1213/00000539-199402000-00006

[26] M. P. Yeager, D. D. Glass, R. K. Neff and T. BrinckJohnsen, "Epidural Anesthesia and Analgesia in High Risk Surgical Patients,” Anesthesiology, Vol. 66, No. 6, 1987, pp. 729-736. doi:10.1097/00000542-198706000-00004

[27] S. Malik, O. Boyko, N. Atkar and W. F. Young, “A Comparative Study of MR Imaging Profile of Titanium Pedicle Screws,” Acta Radiologica, Vol. 42, No. 3, 2001, pp. 291-293. doi:10.1080/028418501127346846 